\title{
Potential radio frequency interference with the GPS L5 band for radio occultation measurements
}

\author{
A. M. Wolff ${ }^{1}$, D. M. Akos ${ }^{2}$, and S. Lo ${ }^{3}$ \\ ${ }^{1}$ Department of Aeronautics and Astronautics, Stanford University, Stanford, California, USA \\ ${ }^{2}$ Department of Aerospace Engineering, University of Colorado, Boulder, Colorado, USA \\ ${ }^{3}$ Department of Aeronautics and Astronautics, Stanford University, Stanford, California, USA
}

Correspondence to: A. M. Wolff (wolffam@stanford.edu)

Received: 19 February 2014 - Published in Atmos. Meas. Tech. Discuss.: 7 May 2014

Revised: 1 October 2014 - Accepted: 6 October 2014 - Published: 18 November 2014

\begin{abstract}
Future radio occultation (RO) receivers are planned to utilize the newly implemented Global Positioning System (GPS) L5 band centered at $1176.45 \mathrm{MHz}$. Since there are currently no operational GPS L5 receivers used for space-based RO applications, the interference environment is unclear. Distance measuring equipment (DME) and tactical air navigation (TACAN) stations share the same frequency band as GPS L5. The signals from these stations have been identified as possible sources of interference for any GPS L5 receiver, including those used in $\mathrm{RO}$ applications. This study utilizes Systems Tools Kit (STK) simulations to gain insight into the power received by a RO satellite in low Earth orbit (LEO) from a DME-TACAN transmission as well as the amount of interfering stations. In order to confirm the validity of utilizing STK for communication purposes, a theoretical scenario was recreated as a simulation and the results were confirmed. Once the method was validated, STK was used to output a received power level aboard a RO satellite from a DME-TACAN station as well as a tool to detail the number of interfering DME-TACAN stations witnessed by a space-based RO receiver over time. The results indicated a large number of DME-TACAN stations transmitting at similar orientations as a receiving RO satellite, thereby leading to the possibility of signal degradation in an unclear interference environment.
\end{abstract}

\section{Introduction}

The Global Positioning System (GPS) L5 band centered at $1176.45 \mathrm{MHz}$ is now being transmitted with the latest IIF satellite design (Van Dierendonck et al., 2000). This signal is part of the GPS modernization effort and offers civil users additional power, a higher chipping rate, and an updated signal modulation structure. As such, it is a promising signal transmission for scientific applications of GPS.

However, certain aeronautical navigation systems already occupy this frequency range. Distance measuring equipment (DME) and tactical air navigation (TACAN) systems offer potential sources of interference due to coexistence within the L5 band (Kim and Grabowski, 2003). These systems are comprised of an airborne interrogator and a ground-based transponder. A TACAN system is essentially a higher powered DME station used for military purposes. Due to the limited placements available within the Aeronautical Radio Navigation Services (ARNA) radio band for aviation use, the GPS L5 signal was placed within the already existing DME-TACAN band. The premise was that an aircraft using the system would only encounter a limited number of pulsed interfering signals, thereby allowing the interoperability between a GPS L5 receiver and a DME-TACAN signal. However, due to the higher number of interfering stations seen by a GPS radio occultation (RO) satellite in low Earth Orbit (LEO), the possibility for signal degradation for RO applications exists (Kim and Grabowski, 2003).

Interference incurred due to the coexistence of these systems degrades the carrier-to-noise ratio (C / No) of a GPS L5 receiver. However, the compatibility of these systems is sufficient for most applications. The low power of a received GPS 
L5 signal for terrestrial users on Earth from the GPS satellites has little if any impact for DME-TACAN operators. Furthermore, the pulsed localized nature of the DME-TACAN signals has minimal impact on terrestrial GPS L5 users as there are limited DME-TACAN sources in close proximity to any terrestrial user and code division multiple access (CDMA) modulation of GPS is robust against pulsed interference.

While most users of GPS L5 will experience minimal degradation from DME-TACAN interference, GPS RO is one such application in which even a slight degraded C / No would have a significant impact on results. This system is implemented today for use in weather forecasting and has been proven to be a very powerful and reliable tool. The architecture of a GPS RO system consists of a satellite in LEO receiving a signal from a GPS satellite. The LEO satellite houses a set of antennas pointed towards the limb of the Earth in order to detect and measure refraction as the signal propagates through the Earth's atmosphere. As a result of this directive orientation of the receiving antenna, these satellites may incur DME-TACAN interference that could obstruct RO data collection. The architecture of GPS RO will be discussed in further detail in the following section.

\section{Background}

\subsection{Radio occultation}

The utilization of GPS RO in weather forecasting has spurred a further advancement in forecasting accuracy. Utilizing the GPS satellite network, RO techniques leverage the stability and global coverage of the GPS network in order to provide higher-accuracy temperature, pressure, and humidity data (Healy et al., 2005). The process involves a sounding technique where a satellite emits a radio wave whose path is then perturbed by an intervening planetary atmosphere before reaching the receiver (Kursinski et al., 1997). Earth-based RO specifically involves a GPS satellite transmitting a signal to a receiving satellite orbiting in LEO. After the transmitted radio wave is refracted, phase and amplitude variation at the receiver is observed over time in order to define the refractive properties of the surrounding atmosphere (Melbourne, 2004). The refraction of the signal causes an excess phase in the dual-frequency carrier phase results as seen by the GPS receiver in LEO (Ware et al., 1996). By observing the degree of refraction, one can gain insight into the vertical distribution of atmospheric pressure, temperature, and humidity. The atmospheric depth of RO retrievals is currently limited by the available signal-to-noise Ratio (SNR). Additional SNR and increased signal-to-interference-plus-noise ratio (SINR) would allow for lower atmospheric data to be obtained.

Previous Earth-based occultation missions, such as GPS-Met and CHAMP (CHAllenging Minisatellite Payload), improved upon numerical weather prediction (NWP) models when compared against the industry standard (Healy et al., 2005). All previous missions have utilized the L1 and L2 GPS frequencies and have exceeded expectations with respect to weather forecasting (Melbourne, 2004). However, the planned implementation of the L5 frequency in a dual-frequency configuration offers an opportunity to improve upon these results. The Formosat-7/COSMIC-2 (Constellation-Observing System for Meteorology, Ionosphere, and Climate) mission is a future joint mission between Taiwan and the United States that aims to utilize L5 receivers for reasons of increased power, overall improvement of signal structure, and the civil designation of the transmission (Mannucci et al., 2012). The TriG (TriGPS-GNSS-RO) receiver is one such receiver developed to utilize these characteristics of the L5 band (Esterhuizen et al., 2009).

\subsection{Distance measuring equipment}

The architecture of the DME system offers a method to determine distance from an aircraft to a ground station (Fisher, 2004). The DME architecture is comprised of an airborne interrogator and a ground-based transponder that operates in four codes $(X, Y, W, Z)$. However, the $X$ code is the only possible interferer with respect to the L5 frequency. The aircraft interrogates within a frequency range of $1025-1150 \mathrm{MHz}$, whereas the ground station transmits over frequencies between 1151 and $1213 \mathrm{MHz}$ within $X$ mode (Bastide et al., 2004). Therefore, any airborne interrogation within this architecture does not directly impinge upon any signal transmitted over the L5 frequency. A number of DME-TACAN ground stations, however, transmit within this frequency range and could become a source of interference for L5 transmissions. For this reason, DME-TACAN ground stations will be the focus for determining interoperability within the L5 frequency for GPS RO applications.

A DME ground station transmits in pulse pairs with a pulse period of $12 \mu \mathrm{s}$ and a half-amplitude pulse width of $3.5 \mu \mathrm{s}$ (Ostermeier, 2010). This signal structure can be seen in Fig. 1. In addition, DME stations either operate at a high power of $1000 \mathrm{~W}$ or at a low power of $100 \mathrm{~W}$. During peak activity, a DME station transmits up to 2700 pulse pairs per second. The effective width of each pulse is defined to be $8 \mu \mathrm{s}$ taking into account a $1 \mu \mathrm{s}$ desaturation time for the receiver. Using this effective pulse width and the pulse pair rate previously defined, a single DME pulse duty cycle is calculated to be $0.0432 \mathrm{~s}^{-1}$ (Roturier, 2001). Therefore, a single DME transmitter at its peak is seen $4.32 \%$ of the time by an L5 receiver.

A TACAN station has many of the same characteristics as a DME station. However, unlike DME stations which transmit at a constant power of 100 or $1000 \mathrm{~W}$, a TACAN station's transmission power ranges cyclically (sinusoidally at 135 and $15 \mathrm{~Hz}$ ) up to $3500 \mathrm{~W}$. These stations are consequently highpowered military versions of their DME counterpart. 


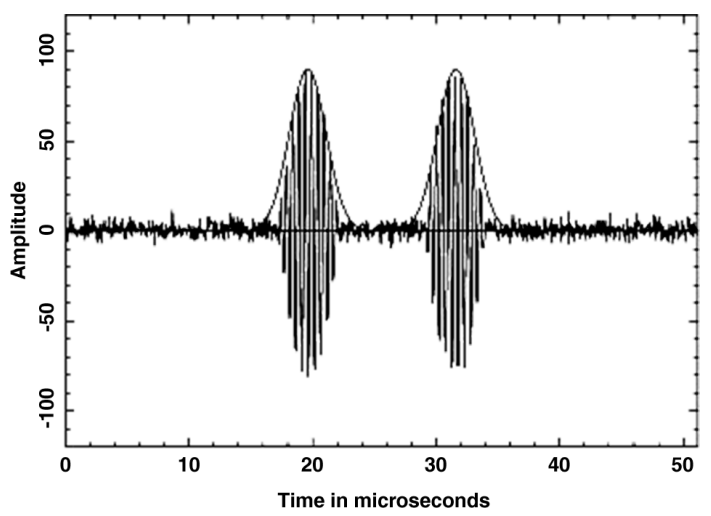

Figure 1. DME pulse pair measured at the Green Bank Telescope in West Virginia (Fisher, 2004).

A standard ground-based DME antenna gain pattern is maximum at $4^{\circ}$ in elevation above the horizon and is omnidirectional in the azimuth. This orientation slightly above the horizon directly aligns with the directional gain pattern of a GPS RO satellite. The peak gain is $+9.5 \mathrm{dBi}$ and the $3 \mathrm{~dB}$ beamwidth is $6^{\circ}$ in elevation with vertical linear polarization (dB Systems Inc., 2013). As the orbiting satellite scans the limb of the Earth, gathering atmospheric data, it is in the main lobe of the directional beam of the DME station for a short period of time.

The United States and western Europe have high concentrations of DME stations, possibly inhibiting a GPS L5 RO receiver in LEO from properly functioning as the difference here is that the satellite will be illuminated by multiple DME stations. In the United States alone there are approximately 203 DME or TACAN ground stations that transmit within $\pm 10 \mathrm{MHz}$ of the $\mathrm{L} 5$ center frequency of $1176.45 \mathrm{MHz}$. In assessing the impact to GPS RO, this is likely a conservative approach due to the fact that some RO receivers have wider bandwidths than $\pm 10 \mathrm{MHz}$ (Esterhuizen et al., 2009). A receiver with a wider bandwidth will encounter a higher number of interfering DME stations. This is troubling for GPS RO scenarios because it offers up the possibility of receiver saturation, a situation in which no valid atmospheric data can be retrieved (ITU, 1998). Furthermore, the directive orientation of the receiver antenna pattern aboard a RO satellite with respect to a DME station increases the received power level from a DME station, increasing the cause for concern.

\section{Pikes Peak L5 data collection}

In order to assess the degree to which a directive antenna amplifies DME interference, it is useful to extract and analyze a real-world interference environment in which two separate antennas were compared. On 21 October 2011, data were collected on top of Pikes Peak mountain in Colorado at an elevation of approximately $4320 \mathrm{~m}$ by a team from the Uni-

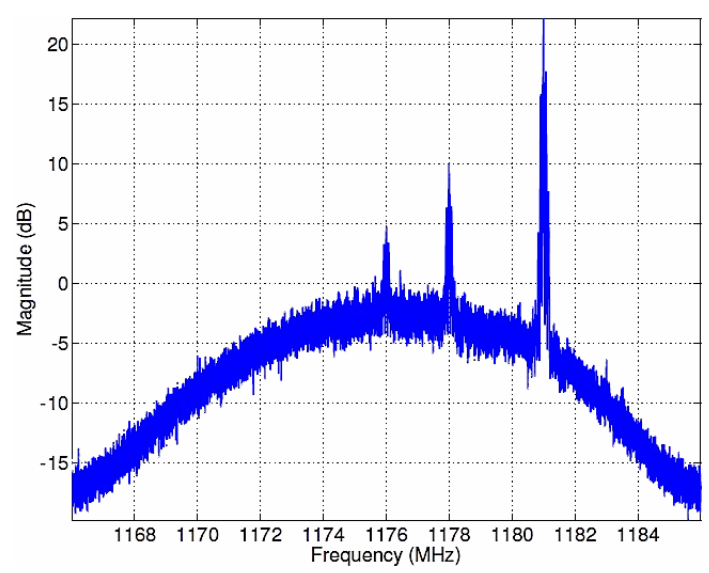

Figure 2. Fourier transform of the time domain into the frequency domain as seen by a helical antenna atop Pikes Peak after postprocessing. This measurement was taken on 21 October 2012 at 17:30 UTC.

versity of Colorado Boulder with the intention of conducting a ground-based RO measurement (Griggs, 2012). This test scenario was constructed in order to gain an understanding of the potential of the new GPS L5 signal for space-based RO. Collections of data from L1, L2, and L5 frequencies were gathered with two separate antennas. The first was a hemispherical survey grade antenna oriented vertically with approximately $-3 \mathrm{dBi}$ gain toward the azimuth. The second was a helical antenna oriented horizontally and pointed $38^{\circ}$ in the azimuth measured clockwise from north. The latter has a peak gain of $+10 \mathrm{dBi}$ and a $3 \mathrm{~dB}$ beamwidth of $45^{\circ}$. The antenna used was the Q-par QHACP 1.2-1.6 GHz (Steatite Ltd., 2014). Since the data sheet is no longer available, a comparable helical antenna is the HE-0238-6. (R. A. Mayes Company Inc., 2014). Although this test cannot directly represent the results that a space-based receiver would yield, the data collected from this study have provided an insight into the amplification of DME signals when a high-gain antenna is employed. Further analysis seeking out the relative power values is currently ongoing.

Although the strength of the interference will undoubtedly be weaker in space, there will be a sharp rise in the number of DME stations affecting the GPS RO receiver. Within the L5 component of this collection, DME pulses can be seen within the data set. Figure 2 offers a depiction of the frequency domain as seen by the helical antenna pointed approximately northeast of Pikes Peak. Noting that the center frequency is $1176 \mathrm{MHz}$, DME stations transmitting at frequencies of 1176,1178 , and $1181 \mathrm{MHz}$ can be seen within the collection. These frequencies correspond to DME stations in Gill, Colorado Plains, and Denver as shown in Fig. 3. On the other hand, DME interference is not directly observed in the data set collected by a survey grade antenna. The reason for this contrast is the differing orientations of the two antennas. The side-by-side comparison shown in Figs. 4 and 5 illuminates 


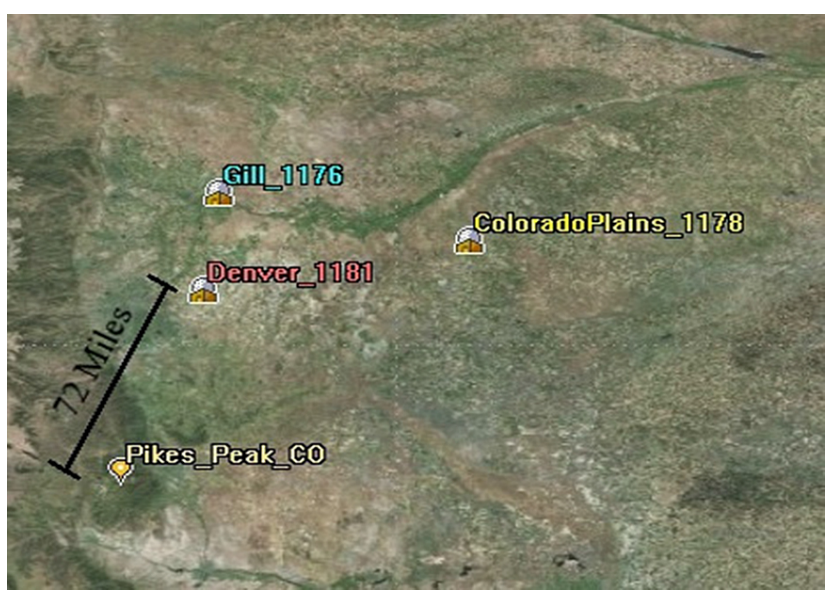

Figure 3. DME and TACAN stations encountered within Pikes Peak measurement as noted in Fig. 2. The helical antenna atop Pikes Peak was pointed $38^{\circ}$ in the azimuth relative to north.

this stark contrast of interference between the data gathered by both antennas.

The interference experienced by the helical antenna registered considerably higher, greater than the thermal noise floor. The helical antenna is focused on the area of interest and therefore gathers visible DME interference. Similarly, a GPS L5 receiver used for RO applications utilizes a highgain directive antenna whose gain is focused on the limb of the Earth (Wu et al., 2005). Further analysis was conducted in order to detail the interference that a GPS RO satellite may encounter due to DME pulses.

\section{Systems Tool Kit validation}

Systems Tool Kit (STK) was utilized to attain a link budget for the received power of a DME station by a satellite in LEO. In order to establish the credibility of a space-based STK simulation, a scenario of a theoretical calculation was reconstructed within STK, and the results were compared to the theoretical solution. Roturier (2001) calculates the minimum pulse peak power at an aircraft's GPS receiving antenna under certain conditions. He defines the scenario as a receiving aircraft flying at an altitude of $12192 \mathrm{~m}$ and a transmitting DME station located on the radio horizon from the aircraft's perspective. Both antennas were modeled as isotropic, and the DME radiated peak power, $P_{e}$, was set at $40 \mathrm{dBW}$. Inputting these specifications in Eq. (1) below yields an approximate minimum peak power received, $P_{1}$, of $-107 \mathrm{dBW}$, where $G$ is the gain of the airborne GPS antenna set at $0 \mathrm{~dB}$, $\lambda$ represents the signal's wavelength equal to $25.5 \mathrm{~cm}$, and $d$ is the distance between transmitter and receiver equivalent to $246 \mathrm{NM}$.

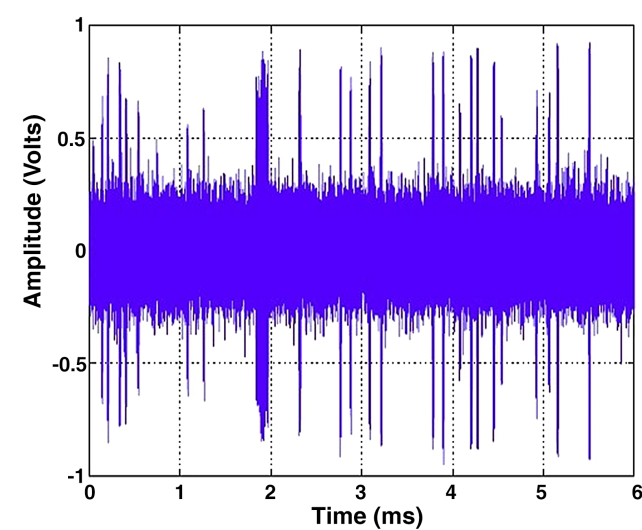

Figure 4. Time domain as seen by helical antenna atop Pikes Peak after signal processing. Measurement taken on 21 October 2012 at 17:30 UTC.

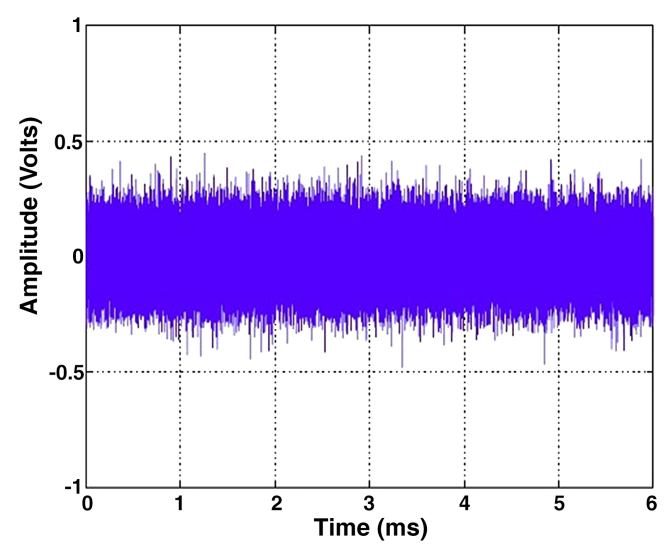

Figure 5. Time domain as seen by a standard survey grade antenna (hemispherical) atop Pikes Peak after signal processing. Measurement taken on 21 October 2012 at 17:30 UTC.

$P_{1}=P_{e} G\left(\frac{\lambda}{4 \pi d}\right)^{2}$

Although Roturier (2001) simplifies this scenario by using isotropic antennas for both the DME stations and the GPS receiver, these identical parameters were recreated within STK and the results were compiled. The STK simulation outputted a value of $-106.91 \mathrm{dBW}$ for the minimum pulse peak power received. The accuracy of this result when compared to the theoretical value supplies a level of integrity for using STK to compute a communication link budget.

\section{STK simulation and link budget results}

In order to estimate the received power levels and range of a DME ground station as seen by a satellite in LEO, a simulation modeling these conditions was constructed within 


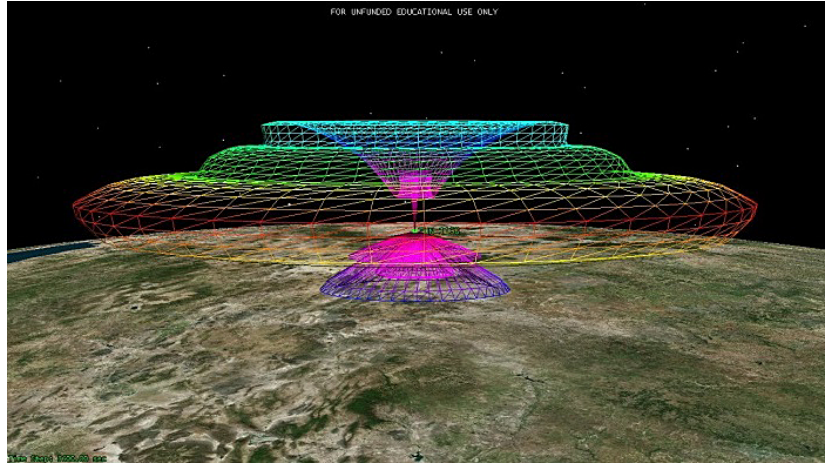

Figure 6. Systems Tool Kit model of dB Systems 5100A DME antenna pattern (Systems Tool Kit, 2014). Figure 10 provides a plot of the gain pattern with respect to elevation.

STK. A satellite database within STK was used to insert the Formosat-3 FM4 satellite into the simulation. This satellite is one of six in a constellation currently commissioned under the COSMIC-1 mission. The selection of this satellite therefore lends an accurate portrayal of a satellite that would house an $\mathrm{L} 5$ receiver for future $\mathrm{RO}$ missions. The gain pattern for the satellite's antenna was modeled in STK and the fore and aft elevation angles were set at $27.38^{\circ}$ and $27.16^{\circ}$, scanning the limb of the Earth (Griggs, 2012). A single DME station was placed in Boulder, Colorado, for testing purposes, and a custom antenna pattern was modeled after the dB Systems Inc. 5100A high-performance DME antenna available on their website (dB Systems Inc., 2013). It should be noted that this model was chosen only as a representative pattern. Figure 6 is an image of the modeled gain pattern within STK.

The transmission power of the DME station was set at $1000 \mathrm{~W}$. This value was chosen based upon the fact that DME stations most commonly transmit at this high-power setting. It should be recalled that this model does not account for the low DME power setting of $100 \mathrm{~W}$ and the dynamic power ranges of a TACAN that can reach $3500 \mathrm{~W}$. With the standard DME model in place, the simulation was progressed over a period of 6 months within STK, and a plot of the results is illustrated in Fig. 7.

The plot demonstrates a color-coded map of the received power with respect to the COSMIC satellite's position over the United States. This simulation indicates that, under ideal conditions, a DME transmission is received by the satellite at a maximum power level of $-123 \mathrm{dBW}$. This power level reaches a maximum when the satellite is within the main beam of the DME antenna. The received power then lessens until it abruptly ends as the satellite loses line of sight with the DME station.

In order to evaluate whether receiver saturation will be a potential problem for GPS RO satellites, an estimation of the time a single DME station interferes with a GPS L5 receiver and the total number of DME stations interfering at a given point in time are required. Due to the pulsed na-

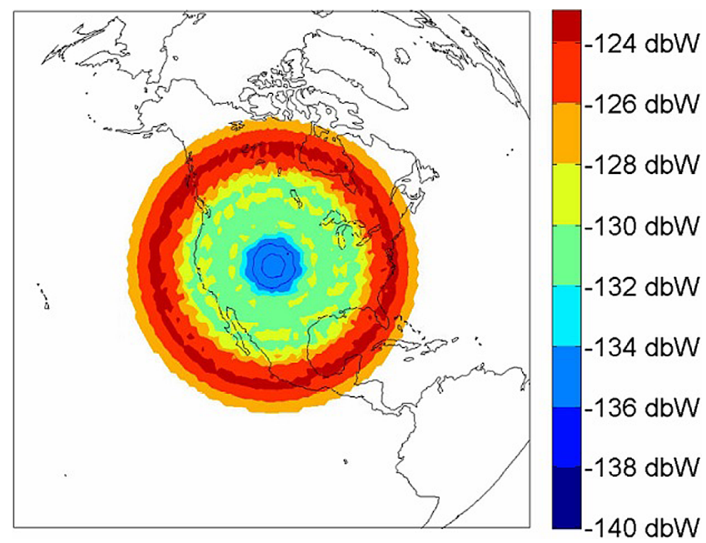

Figure 7. Formosat-3 FM4 satellite received power from a single DME station located at $39.8125^{\circ}$ latitude and $-104.661^{\circ}$ longitude. Results gathered from STK simulation.

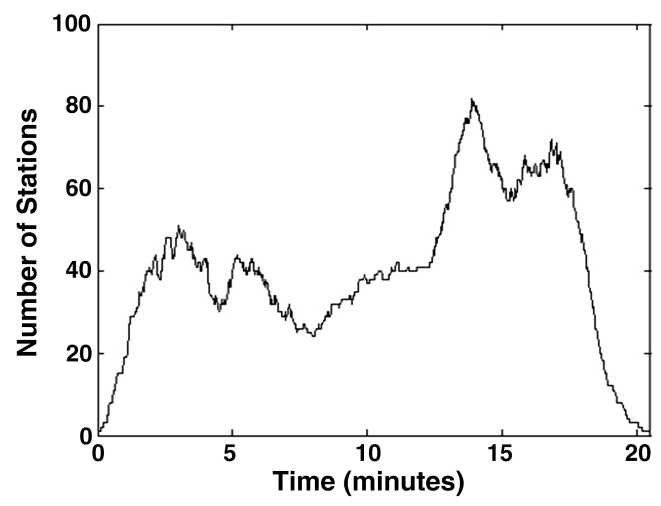

Figure 8. Number of interfering DME stations with received power levels above $-125 \mathrm{dBW}$ with respect to time as seen by the Formosat-3 FM4 satellite on 8 January 2013 from 16:02:21 to $16: 22: 50$ UTC. The figure details the satellites orbit across the United States from New Mexico to North Dakota and reaches a maximum when the satellite is orbiting over Manitoba, Canada. Results gathered from STK simulation.

ture of a DME signal, a GPS L5 receiver technically will not experience the DME transmission at all times. Recalling the calculated duty cycle of $4.3 \%$ for a single DME station offers an estimate for the maximum time a DME station may transmit every second. In order to estimate how many DME stations would be interfering with a receiver in LEO at any given time, STK was utilized to provide the number of stations whose received power was greater than $-125 \mathrm{dBW}$, which was provided as an arbitrary constraint.

All 203 relevant DME stations were inserted into STK, and the number of interferers with respect to time was computed as the Formosat-3 FM4 satellite with the same antenna parameters as the previous STK simulation starting in the South Pacific Ocean traveled over the United States from New Mexico up towards North Dakota until all connections were lost in northern Canada. See Table 1 for the list of the 


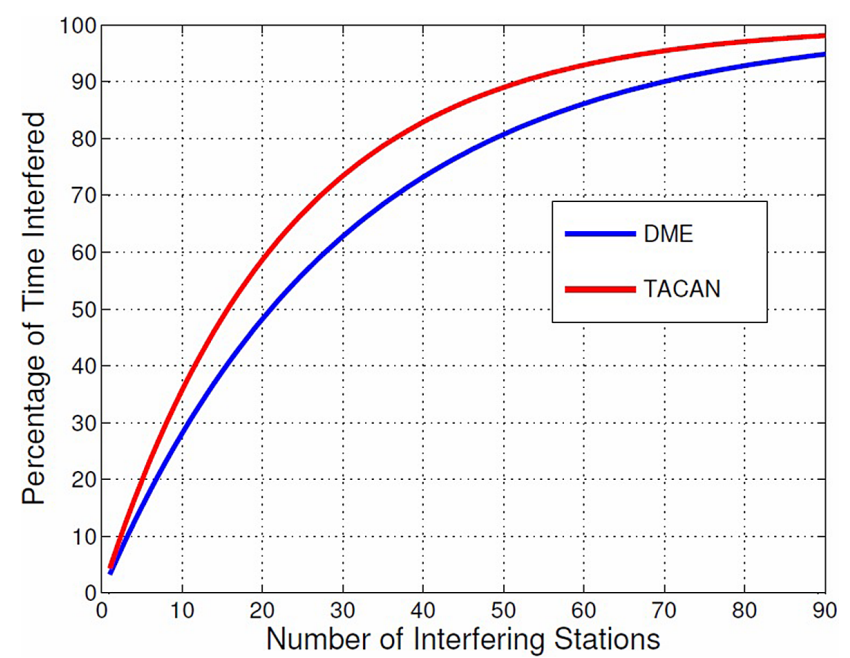

Figure 9. Percentage of time interfered as a function of the number of stations. This percentage is calculated through the use of Eq. (2).

relevant DME stations. The resulting plot is shown in Fig. 8 . This figure indicates a maximum number of 82 stations transmitting with received powers of above $-125 \mathrm{dBW}$. This extreme case occurred when the satellite was over Manitoba, Canada. Due to the orientation of the DME gain pattern, it is consistent with the results that the highest concentration of signal is found on the edge of the network, not directly overhead. Due to the large amount of DME stations encountered by a space-based receiver, an overlap of the pulsed DME transmissions will occur. A separate calculation was implemented to provide insight into this overlap of the pulsed signals. The curves depicted in Fig. 9 illustrate the percentage of the time a receiver is being interfered with by DME and TACAN stations. The following equation defines this scenario as the number of interfering stations approaches 90 , where $I$ is the percent of time interfered, $D$ is the duty cycle of a DME signal equivalent to $4.32 \%$, and $N$ is the number of DME stations.

$I=1-(1-D)^{N}$

\section{Conclusions}

A real-world validation of any simulation within STK is currently impossible due to the lack of space-based L5 GPS receivers with a representative RO pattern. With the future implementation of L5 receivers in space, the opportunity for experimental testing will be realized. However, without full knowledge of the parameters and conditions that a specific DME-TACAN station was operating under at the exact time of the data collection, any experiment will inherently be flawed. Uncertainties in specific antenna patterns, antenna efficiencies, receiver noise figure and other unknown variables

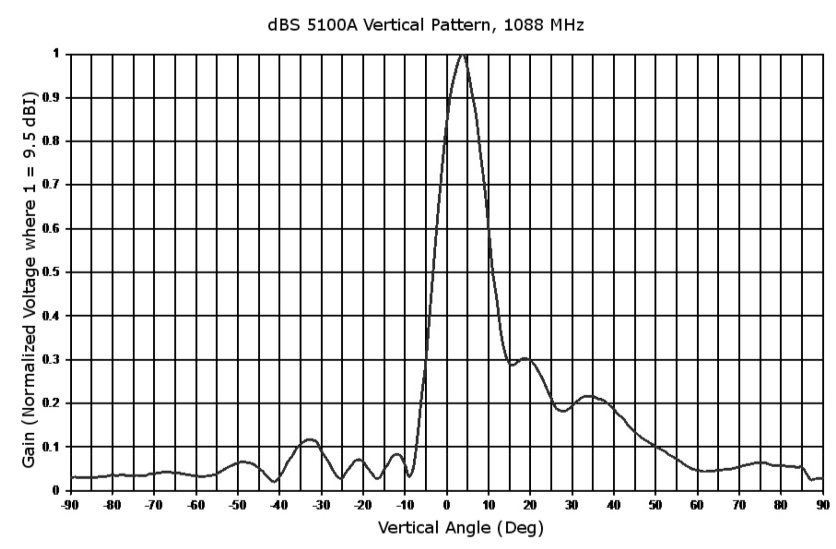

Figure 10. Plot of the gain pattern of 5100A DME antenna with respect to elevation angle (dB Systems Inc., 2013).

obscure any reasonable result. Although a space-based test cannot currently be conducted, other tests were undertaken in order to add to the credibility of the space-based STK simulation.

The single transmitting DME station and orbiting RO satellite simulation yielded a maximum received power level of $-123 \mathrm{dBW}$. A separate STK simulation including all of the relevant DME stations in the United States indicated that a GPS RO receiver in LEO may witness more than 80 stations at a time with received power levels above $-125 \mathrm{dBW}$. This number of relatively high-powered transmissions may cause substantial interference and possible saturation for a spacebased GPS L5 receiver.

The resultant maximum received power should be noted as a conservative estimate due to restricting the study of the RO receiver bandwidth to within $\pm 10 \mathrm{MHz}$ of the center frequency of $1176.45 \mathrm{MHz}$. Many RO receivers utilize a wide bandwidth with limited filtering in order to optimize data collection. However, this study implies that this approach may prove to have an adverse effect on the receivers' ability to gather data due to a greater number of interfering DME stations within the collected frequencies.

The resultant values may still not portray an entirely accurate estimate due to possible inaccuracies embedded in custom antenna patterns as well as the specific orientations for the antennas. A detailed analysis specifying correct transmission powers for each station could yield different results; however, using a $1000 \mathrm{~W}$ transmission power appears to be a suitable approach.

With these considerations in mind, the results gathered from the STK simulations indicate that L5 GPS receivers in LEO may experience interference caused by DME and TACAN stations, resulting in the possible saturation of the receivers. For the application of radio occultation, this interference could result in a loss of collected data as the satellite orbits over regions highly populated with DME stations, namely the United States and western Europe. 
Table 1. Name, location, and corresponding transmission frequency of DME-TACAN stations within $\pm 10 \mathrm{MHz}$ of $1176.45 \mathrm{MHz}$ in the United States.

\begin{tabular}{|c|c|c|c|c|}
\hline Name & Symbol & Freq $(\mathrm{MHz})$ & Latitude & Longitude \\
\hline ABILENE & $\mathrm{ABI}$ & 1171 & 32.481328 & -99.863456 \\
\hline ALBUQUERQUE & $\mathrm{ABQ}$ & 1166 & 35.043797 & -106.816314 \\
\hline AKRON & $\mathrm{ACO}$ & 1178 & 41.107903 & -81.201511 \\
\hline AKRON & $\mathrm{AKO}$ & 1178 & 40.155578 & -103.179739 \\
\hline ALAMOSA & ALS & 1173 & 37.349158 & -105.815536 \\
\hline ALMA & AMG & 1185 & 31.536531 & -82.508081 \\
\hline ARMEL & AML & 1169 & 38.934597 & -77.466694 \\
\hline NAPOLEON & ANX & 1174 & 39.095425 & -94.128836 \\
\hline WALNUT RIDGE & ARG & 1179 & 36.109997 & -90.953669 \\
\hline ASTORIA & AST & 1174 & 46.161689 & -123.880364 \\
\hline BALTIMORE & BAL & 1185 & 39.171064 & -76.661256 \\
\hline BRADFORD & $\mathrm{BDF}$ & 1181 & 41.159731 & -89.587872 \\
\hline BANGOR & BGR & 1182 & 44.8418 & -68.873964 \\
\hline BIG SPRING & BGS & 1177 & 32.385589 & -101.483683 \\
\hline BILLINGS & BIL & 1179 & 45.808561 & -108.624669 \\
\hline NASHVILLE & BNA & 1175 & 36.136961 & -86.684772 \\
\hline BOISE & BOI & 1167 & 43.552811 & -116.192131 \\
\hline BEAUMONT & BPT & 1179 & 29.946056 & -94.016222 \\
\hline BULLION & BQU & 1179 & 40.759675 & -115.761367 \\
\hline BROOKE & BRV & 1179 & 38.336283 & -77.352903 \\
\hline BIG SUR & BSR & 1174 & 36.181294 & -121.642114 \\
\hline BEATTY & BTY & 1181 & 36.800583 & -116.747647 \\
\hline BYERS & BVR & 1169 & 39.765833 & -103.928044 \\
\hline BOILER & BVT & 1185 & 40.556119 & -87.069319 \\
\hline BROADWAY & BWZ & 1176 & 40.798433 & -74.821833 \\
\hline BURLEY & BYI & 1175 & 42.580244 & -113.865853 \\
\hline BONHAM & BYP & 1180 & 33.537486 & -96.234094 \\
\hline COLUMBIA & CAE & 1181 & 33.857247 & -81.053906 \\
\hline CAMBRIDGE & CAM & 1184 & 42.994289 & -73.344019 \\
\hline CHADRON & CDR & 1168 & 42.558772 & -103.312147 \\
\hline CHICAGO HEIGHTS & CGT & 1176 & 41.510006 & -87.571544 \\
\hline CHARLESTON & $\mathrm{CHS}$ & 1169 & 32.894319 & -80.037814 \\
\hline CEDAR RAPIDS & CID & 1175 & 41.887533 & -91.785706 \\
\hline CHEROKEE & CKW & 1184 & 41.755708 & -107.581983 \\
\hline COLLEGE STATION & CLL & 1167 & 30.605003 & -96.420681 \\
\hline CHARLOTTE & CLT & 1184 & 35.190472 & -80.952 \\
\hline CEDAR CREEK & CQY & 1182 & 32.185722 & -96.218103 \\
\hline CRAIG & CRG & 1179 & 30.338861 & -81.509944 \\
\hline CUT BANK & СТВ & 1178 & 48.564944 & -112.34325 \\
\hline CHESTER & CTR & 1185 & 42.291319 & -72.949394 \\
\hline DAVENPORT & CVA & 1172 & 41.708542 & -90.483306 \\
\hline COFIELD & CVI & 1180 & 36.372914 & -76.871544 \\
\hline COYLE & CYN & 1168 & 39.817314 & -74.431622 \\
\hline DAGGETT & DAG & 1166 & 34.962458 & -116.578167 \\
\hline DOLPHIN & DHP & 1173 & 25.799964 & -80.349036 \\
\hline DRYER & DJB & 1170 & 41.358064 & -82.161969 \\
\hline DAYTON & DQN & 1179 & 40.016419 & -84.396872 \\
\hline DUPONT & DQO & 1174 & 39.678147 & -75.607092 \\
\hline DRAKE & DRK & 1175 & 34.702583 & -112.48025 \\
\hline DOVE CREEK & DVC & 1180 & 37.808739 & -108.931272 \\
\hline MILE HIGH & DVV & 1181 & 39.894694 & -104.624333 \\
\hline DETROIT & DXO & 1168 & 42.213136 & -83.366664 \\
\hline PECK & ECK & 1174 & 43.255886 & -82.717931 \\
\hline NEEDLES & EED & 1186 & 34.766003 & -114.474103 \\
\hline
\end{tabular}


Table 1. Continued.

\begin{tabular}{|c|c|c|c|c|}
\hline Name & Symbol & Freq $(\mathrm{MHz})$ & Latitude & Longitude \\
\hline ELKINS & $\mathrm{EKN}$ & 1176 & 38.914436 & -80.099272 \\
\hline MEEKER & EKR & 1186 & 40.067472 & -107.924881 \\
\hline EL PASO & ELP & 1186 & 31.815911 & -106.281883 \\
\hline CENTRALIA & ENL & 1184 & 38.420022 & -89.159017 \\
\hline PEOTONE & EON & 1166 & 41.269639 & -87.791053 \\
\hline KEWANEE & EWA & 1172 & 32.366808 & -88.458369 \\
\hline NEW BERN & EWN & 1170 & 35.073131 & -77.045058 \\
\hline KEY WEST & EYW & 1169 & 24.585878 & -81.800475 \\
\hline FLAT ROCK & FAK & 1167 & 37.528508 & -77.828219 \\
\hline KALISPELL & FCA & 1166 & 48.214103 & -114.175892 \\
\hline FORT LAUDERDALE & FLL & 1178 & 26.074739 & -80.152472 \\
\hline FLORENCE & FLO & 1186 & 34.232933 & -79.657114 \\
\hline FORT DODGE & FOD & 1169 & 42.611167 & -94.294833 \\
\hline FORTUNA & FOT & 1174 & 40.671272 & -124.234539 \\
\hline WILLIAMSPORT & FQM & 1178 & 41.338556 & -76.774861 \\
\hline SIOUX FALLS & FSD & 1184 & 43.649531 & -96.781164 \\
\hline GILLETTE & GCC & 1180 & 44.347772 & -105.543486 \\
\hline GARDEN CITY & GCK & 1167 & 37.919053 & -100.725064 \\
\hline GRAND FORKS & GFK & 1177 & 47.954833 & -97.185369 \\
\hline GOFFS & GFS & 1178 & 35.131144 & -115.176442 \\
\hline GLASGOW & GGW & 1173 & 48.215269 & -106.625461 \\
\hline GOODLAND & GLD & 1185 & 39.387861 & -101.692306 \\
\hline GILL & GLL & 1176 & 40.503869 & -104.553014 \\
\hline GOSHEN & GSH & 1171 & 41.525186 & -86.027972 \\
\hline GREAT FALLS & GTF & 1185 & 47.449981 & -111.412164 \\
\hline GUTHRIE & GTH & 1179 & 33.778278 & -100.336197 \\
\hline GALLUP & GUP & 1185 & 35.476 & -108.872611 \\
\hline GAVIOTA & GVO & 1172 & 34.531308 & -120.091083 \\
\hline BLUE MESA & $\mathrm{HBU}$ & 1183 & 38.452153 & -107.039792 \\
\hline HARTFORD & HFD & 1183 & 41.641106 & -72.547417 \\
\hline WHITEHALL & HIA & 1171 & 45.861797 & -112.169597 \\
\hline HILL CITY & HLC & 1171 & 39.258747 & -100.22585 \\
\hline HALLSVILLE & HLV & 1176 & 39.113542 & -92.128233 \\
\hline HOLSTON MOUNTAIN & HMV & 1180 & 36.437056 & -82.1296 \\
\hline HARVEY & HRV & 1175 & 29.850194 & -90.002983 \\
\hline HAMPTON & HTO & 1170 & 40.919017 & -72.316694 \\
\hline HUDSPETH & HUP & 1184 & 31.568703 & -105.376319 \\
\hline SCREAMING EAGLE & HXW & 1183 & 36.675603 & -87.495011 \\
\hline EL NIDO & HYP & 1176 & 37.219431 & -120.400217 \\
\hline HAYWARD & HYR & 1168 & 46.019006 & -91.4464 \\
\hline HAZEN & $\mathrm{HZN}$ & 1175 & 39.516414 & -118.997689 \\
\hline WICHITA & ICT & 1172 & 37.745258 & -97.583831 \\
\hline KINGFISHER & IFI & 1181 & 35.805267 & -98.003917 \\
\hline LOUISVILLE & IIU & 1182 & 38.103464 & -85.577436 \\
\hline WILLIAMS & ILA & 1178 & 39.07115 & -122.027244 \\
\hline WILDHORSE & ILR & 1172 & 43.593122 & -118.955044 \\
\hline KIRKSVILLE & IRK & 1180 & 40.135022 & -92.591714 \\
\hline COLLIERS & IRQ & 1173 & 33.707353 & -82.162064 \\
\hline WILL ROGERS & IRW & 1175 & 35.358589 & -97.609233 \\
\hline WILLIE & IWA & 1167 & 33.303175 & -111.651442 \\
\hline GLEN ROSE & JEN & 1184 & 32.159589 & -97.877681 \\
\hline JEFFERSON & JFN & 1186 & 41.760122 & -80.748106 \\
\hline JAMESTOWN & JHW & 1181 & 42.188608 & -79.121306 \\
\hline JULIAN & JLI & 1174 & 33.140458 & -116.585936 \\
\hline JAMESTOWN & JMS & 1179 & 46.932872 & -98.678769 \\
\hline
\end{tabular}


Table 1. Continued.

\begin{tabular}{|c|c|c|c|c|}
\hline Name & Symbol & Freq $(\mathrm{MHz})$ & Latitude & Longitude \\
\hline JANESVILLE & JVL & 1177 & 42.557986 & -89.105306 \\
\hline JUNIOR & JYU & 1170 & 32.344611 & -86.991269 \\
\hline LOS ANGELES & LAX & 1170 & 33.933422 & -118.432431 \\
\hline LAKE CHARLES & $\mathrm{LCH}$ & 1168 & 30.141514 & -93.105569 \\
\hline LUCIN & LCU & 1170 & 41.362953 & -113.840619 \\
\hline LINDEN & LDN & 1177 & 38.854392 & -78.205556 \\
\hline LEBANON & LEB & 1171 & 43.679194 & -72.215083 \\
\hline LEEVILLE & LEV & 1169 & 29.175231 & -90.104019 \\
\hline MARCONI & LFV & 1181 & 42.017172 & -70.037269 \\
\hline LINDEN & LIN & 1182 & 38.074589 & -121.003858 \\
\hline LITTLE ROCK & LIT & 1173 & 34.677672 & -92.180528 \\
\hline SALMON & LKT & 1169 & 45.021311 & -114.084236 \\
\hline MIDLAND & MAF & 1182 & 32.009344 & -102.190389 \\
\hline MARIANNA & MAI & 1174 & 30.786222 & -85.12445 \\
\hline MAPLES & MAP & 1168 & 37.590767 & -91.788569 \\
\hline MACON & $\mathrm{MCN}$ & 1176 & 32.691222 & -83.647181 \\
\hline MASON CITY & MCW & 1183 & 43.094739 & -93.329872 \\
\hline TRINITY & MHF & 1170 & 29.546344 & -94.747514 \\
\hline MANCHESTER & MHT & 1178 & 42.868531 & -71.369544 \\
\hline MUNCIE & MIE & 1178 & 40.237294 & -85.394036 \\
\hline MUSKEGON & MKG & 1186 & 43.169242 & -86.039383 \\
\hline MORMON MESA & MMM & 1177 & 36.769278 & -114.277472 \\
\hline MODESTO & MOD & 1180 & 37.627375 & -120.957867 \\
\hline MASSENA & MSS & 1175 & 44.914444 & -74.722664 \\
\hline MINA & MVA & 1185 & 38.5653 & -118.032853 \\
\hline MARTHAS VINEYARD & MVY & 1179 & 41.396211 & -70.612722 \\
\hline MOSES LAKE & MWH & 1184 & 47.210864 & -119.316817 \\
\hline MODENA & MXE & 1166 & 39.918053 & -75.670797 \\
\hline MOLINE & $\mathrm{MZV}$ & 1178 & 41.321061 & -90.638081 \\
\hline FALLON & NFL & 1169 & 39.416864 & -118.704869 \\
\hline TRUAX & NGP & 1174 & 27.686278 & -97.294742 \\
\hline BRUNSWICK & $\mathrm{NHZ}$ & 1186 & 43.873514 & -69.921911 \\
\hline LEMOORE & NLC & 1167 & 36.344117 & -119.966333 \\
\hline WHIDBEY ISLAND & NUW & 1172 & 48.354936 & -122.661786 \\
\hline YUMA & NYL & 1171 & 32.6468 & -114.613453 \\
\hline WOLBACH & $\mathrm{OBH}$ & 1182 & 41.375736 & -98.353594 \\
\hline OCALA & $\mathrm{OCF}$ & 1171 & 29.177475 & -82.226344 \\
\hline FOOTHILLS & ODF & 1168 & 34.695872 & -83.297661 \\
\hline ROGUE VALLEY & OED & 1170 & 42.479575 & -122.912933 \\
\hline КОКОМО & OKK & 1169 & 40.527789 & -86.058017 \\
\hline OKMULGEE & OKM & 1183 & 35.693097 & -95.865978 \\
\hline OLYMPIA & OLM & 1168 & 46.971639 & -122.901833 \\
\hline O'NEILL & ONL & 1173 & 42.470503 & -98.686922 \\
\hline CHICAGO O'HARE & ORD & 1173 & 41.987672 & -87.904886 \\
\hline WOODSIDE & OSI & 1173 & 37.392672 & -122.281828 \\
\hline VALDOSTA & OTK & 1182 & 30.780444 & -83.279728 \\
\hline NOTTINGHAM & OTT & 1171 & 38.705867 & -76.744744 \\
\hline PENDLETON & PDT & 1181 & 45.698419 & -118.938703 \\
\hline PIONEER & PER & 1166 & 36.746531 & -97.160156 \\
\hline PANAMA CITY & PFN & 1177 & 30.216256 & -85.680942 \\
\hline RICH MOUNTAIN & PGO & 1169 & 34.680456 & -94.609003 \\
\hline PEORIA & PIA & 1186 & 40.680067 & -89.7928 \\
\hline PALMDALE & PMD & 1179 & 34.6314 & -118.063822 \\
\hline PRINCETON & PNN & 1177 & 45.329197 & -67.704203 \\
\hline PASO ROBLES & PRB & 1177 & 35.672469 & -120.627111 \\
\hline PARIS & PRX & 1170 & 33.542378 & -95.448292 \\
\hline
\end{tabular}


Table 1. Continued.

\begin{tabular}{lccrr}
\hline Name & Symbol & Freq $(\mathrm{MHz})$ & Latitude & Longitude \\
\hline PAWLING & PWL & 1177 & 41.769772 & -73.600553 \\
POCKET CITY & PXV & 1167 & 37.928319 & -87.762381 \\
POINT REYES & PYE & 1171 & 38.079756 & -122.867828 \\
RAVINE & RAV & 1180 & 40.553378 & -76.599378 \\
ROBBINSVILLE & RBV & 1172 & 40.202389 & -74.495014 \\
RICHMOND & RIC & 1175 & 37.50235 & -77.320278 \\
KREMMLING & RLG & 1172 & 40.002642 & -106.442489 \\
WORLAND & RLY & 1182 & 43.964139 & -107.950833 \\
REDWOOD FALLS & RWF & 1167 & 44.467275 & -95.128231 \\
SAN MARCUS & RZS & 1183 & 34.509528 & -119.770992 \\
SACRAMENTO & SAC & 1186 & 38.443658 & -121.551622 \\
SOD HOUSE & SDO & 1177 & 41.407056 & -118.034722 \\
SEA ISLE & SIE & 1182 & 39.095503 & -74.800333 \\
SAN JOSE & SJC & 1175 & 37.374711 & -121.944667 \\
SAN ANGELO & SJT & 1185 & 31.374953 & -100.454875 \\
SLATE RUN & SLT & 1173 & 41.512758 & -77.970111 \\
SIDON & SQS & 1181 & 33.463861 & -90.277333 \\
STONEWALL & STV & 1172 & 30.206758 & -98.705756 \\
SALEM & SVM & 1177 & 42.408869 & -83.594189 \\
SQUAW VALLEY & SWR & 1166 & 39.180322 & -120.269614 \\
SAYRE & SYO & 1186 & 35.345161 & -99.635347 \\
TUBA CITY & TBC & 1169 & 36.121325 & -111.269586 \\
TUCUMCARI & TCC & 1170 & 35.182139 & -103.598519 \\
STANFIELD & TFD & 1182 & 32.885856 & -111.908733 \\
ST THOMAS & THS & 1184 & 39.933228 & -77.950944 \\
TWENTYNINE PALMS & TNP & 1176 & 34.112236 & -115.769908 \\
TYRONE & TON & 1183 & 40.735117 & -78.331294 \\
TULSA & TUL & 1178 & 36.196261 & -95.788108 \\
TRAVERSE CITY & TVC & 1180 & 44.667919 & -85.549958 \\
QUITMAN & UIM & 1174 & 32.880403 & -95.366753 \\
QUINCY & UIN & 1170 & 39.847875 & -91.278925 \\
TEXOMA & URH & 1177 & 33.944186 & -96.391836 \\
CEDAR LAKE & VCN & 1186 & 39.537672 & -74.967144 \\
VANDALIA & VLA & 1177 & 39.093683 & -89.162464 \\
MOUNT VERNON & VNN & 1172 & 38.361953 & -88.807336 \\
VULCAN & VUZ & 1178 & 33.670186 & -86.8998 \\
FREEPORT & ZFP & 1166 & 26.555256 & -78.69785 \\
ZUNI & ZUN & 1168 & 34.965753 & -109.154508 \\
\hline & & & & \\
\hline
\end{tabular}

Edited by: M. Nicolls

Occultation Space Receiver, Proceedings of the 22nd International Technical Meeting of The Satellite Division of the Institute of Navigation, Savannah, GA, September 2009, 1442-1446, 2009.

Fisher, J. R.: Signal analysis and blanking experiments on DME interference, National Radio Astronomy Observatory, Electronics Division, Report 313, 2004.

\section{References}

Bastide, F., Chatre, E., Macabiau, C., and Roturier, B.: GPS L5 and Galileo E5a/E5b signal-to-noise density ratio degradations due to DME / TACAN signals: simulations and theoretical derivation, J. Inst. Navig., 26, 1049-1062, 2004.

dB Systems Inc.: available at: http://www.dbsant.com/5100A.php (last access: 20 June 2013), 2013.

Esterhuizen, S., Franklin, G., Hurst, K., Mannucci, A., Meehan, T., Webb, F., Young, L.: TriG - A GNSS Precise Orbit and Radio

Griggs, E.: Ground-based GPS occultation utilizing modernized signals, in: Proceedings of IROWG-2, Estes Park, Colorado, 28 March 2012, 2012.

Healy, S. B., Jupp, A. M., and Marquardt, C.: Forecast impact experiment with GPS radio occultation measurements, Geophys. Res. Lett., 32, L03804, doi:10.1029/2004GL020806, 2005.

International Telecommunication Union (ITU): Feasibility of sharing between radionavigation-satellite service and the earth explo- 
ration satellite (active) and space research (active) services in the 1 215-1 260 MHz BAND, Recommendation RS.1347-0, 1998.

Kim, T. and Grabowski, J.: Validation of GPS L5 coexistence with DME / TACAN and link-16 systems, J. Inst. Navig., 9, 1455-11469, 2003.

Kursinski, E. R., Hajj, G. A., Schofield, J. T., Linfield, R. P., and Hardy, K. R.: Observing Earth's atmosphere with radio occultation measurements using the global positioning system, J. Geophys. Res., 102, 23429-23465, 1997.

Mannucci, A. J., Lowe, S. T., Franklin, G., Meehan, T. K., and Xie, F.: New science opportunities on COSMIC-2/FORMOSAT7, Sixth FORMOSAT-3/COSMIC Data Users' Workshop, 30 October 2012, Boulder, Colorado, 2012.

Melbourne, W. G.: Radio occultations using earth satellites: A wave theory treatment, Deep Space Communications and Navigation Series, Jet Propulsion Lab, California Institute of Technology, Monograph 6, 2004.

Ostermeier, J.: Test of DME / TACAN transponders application note - 1GP74, Rohde and Schwarz Co., Munich, Germany, 5-9, 2010.

R. A. Mayes Company Inc.: available at: http://www.ramayes.com/ helical_antennas.htm (last access: 9 September 2014), 2014.
Roturier, B.: Report on DME interference on GPS/L5, Direction Generale de l'Aviation Civile, Report (Third Version), 9 March 2001.

Steatite Ltd.: available at: http://www.steatiteqpar-antennas.co.uk/ (last access: 9 September 2014), 2014.

Systems Tool Kit: available at: https://www.agi.com/products/ (last access: 2 April 2014), 2014.

Van Dierendonck, A. J., Hegarty, C., Scales, W., and Ericson, S.: Signal specification for the future GPS civil signal at L5, J. Inst Navig., 232-241, 2000.

Ware, R., Rocken, C., Solheim, F., Exner, M., Schreiner, W., Anthes, R., Feng, D., Herman, B., Gorbunov, M., Sokolovskiy, S., Hardy, K., Kuo, Y., Zou, X., Trenberth, K., Meehan, T., Melbourne, W., and Businger, S.: Gps sounding of the atmosphere from low earth orbit: preliminary results, B. Am. Meteorol. Soc., 77, 19-40, doi:10.1175/15200477(1996)077<0019:GSOTAF>2.0.CO;2, 1996.

Wu, B., Chu, V., Chen, P., and Ting, T.: FORMOSAT3/COSMIC science mission update, GPS Solut., 9, 111-121, doi:10.1007/s10291-005-0140-z, 2005. 